Communications in Physics, Vol.20, No. 1 (2010), pp. 51-57

\title{
INFLUENCE OF ADHESION LAYERS ON THE SURFACE MORPHOLOGY OF PLATINUM-BASED BOTTOM ELECTRODES FOR $\mathrm{Pb}(\mathrm{Zr}, \mathrm{Ti}) \mathrm{O}_{3}$ THIN FILMS
}

\author{
NGUYEN THANH HUY \\ Hanoi Advanced School of Science and Technology, \\ Hanoi University of Technology \\ VU NGOC HUNG \\ International Training Institute for Materials Science, \\ Hanoi University of Technology
}

\begin{abstract}
A thin adhesion layer is required to glue Pt bottom electrodes of ferroelectric $\mathrm{Pb}(\mathrm{Zr}, \mathrm{Ti}) \mathrm{O}_{3}$ thin films to a $\mathrm{SiO}_{2} / \mathrm{Si}$ wafer. Here we report the effect of adhesion layers, $\mathrm{Ti}$ and $\mathrm{TiO}_{2}$, on the crystalline structure and surface properties of Pt electrode. The results show the hillock formation is observed for the case of Ti glue layer, while the surface of Pt layer is flat and uniform with $\mathrm{TiO}_{2}$ layer used instead. The crystallization in PZT thin films on Pt/TiO $/ \mathrm{SiO}_{2} / \mathrm{Si}$ substrate is investigated during post-deposition annealing. The perovskite phase is completely formed in the film annealed at $650^{\circ} \mathrm{C}$ for one hour.
\end{abstract}

\section{INTRODUCTION}

In recent years, lead zirconate titanate $\mathrm{Pb}(\mathrm{Zr}, \mathrm{Ti}) \mathrm{O}_{3}(\mathrm{PZT})$ thin films attract much attention of researchers due to their wide potential for important applications in memory and microelectro-mechanical devices $[1,2]$. In most Si-based devices, integrated PZT capacitor structures need to be formed. Among several materials used to fabricate electrodes of the capacitors [3-7], platinum metal is primarily chosen because of its advantages. $\mathrm{Pt}$ has an excellent electric conductivity and chemical stability in high-temperature oxidizing ambience that are necessary for crystallizing PZT perovskite phases, typically in the range of $600-700^{\circ} \mathrm{C}$. It is presented that if a Pt layer is directly deposited on a $\mathrm{SiO}_{2} / \mathrm{Si}$ wafer then the Pt electrode does not easily bond well to the wafer, and also, the formation of Pt-silicide occurs [8]. To prevent, a buffer thin layer of titanium is typically employed, and a $\mathrm{Pt} / \mathrm{Ti}$ bilayer has been widely used as the bottom electrode of the PZT thin films $[3,9,10]$. However, after a post-deposition annealing, the underlying $\mathrm{Pt} / \mathrm{Ti}$ metallization showed up a major instability phenomenon: Pt hillock growth [11-13]. The hillocks may cause the electrical short circuit in the ferroelectric capacitor $[12,14]$. Subsequently, a $\mathrm{TiO}_{2}$ thin layer, instead of $\mathrm{Ti}$, which could keep the Pt film surface to be flat, is considered as a promising candidate to promote the adhesion between the Pt electrode and PZT thin film [15-17].

In this paper, we report the results on investigation of the surface morphology and structure of the Pt electrode fabricated on the substrates with different glue layer of $\mathrm{Ti}$ or 
$\mathrm{TiO}_{2}$. Additionally, the annealing time dependence of crystallizing of the PZT thin films, which are deposited on the $\mathrm{Pt} / \mathrm{TiO}_{2} / \mathrm{SiO}_{2} / \mathrm{Si}$ substrate, is mentioned.

\section{EXPERIMENTAL}

A detailed description about the preparation of $\mathrm{Pt} / \mathrm{Ti}$ electrode was given in the previous work [18]. Ti and $\mathrm{Pt}$ thin films were successionally deposited on $\mathrm{SiO}_{2} / \mathrm{Si}$ wafer under argon ambience from metallic targets by the rf-sputtering method. The thicknesses of $\mathrm{Ti}$ and $\mathrm{Pt}$ layers were 20 and $120 \mathrm{~nm}$, respectively.

For $\mathrm{Pt} / \mathrm{TiO}_{2}$ electrode, $20 \mathrm{~nm}-\mathrm{TiO}_{2}$ layer was formed by two routes: $(i)$ thermally oxidized a sputtered-Ti thin film in oxygen ambience at $750{ }^{\circ} \mathrm{C}$ for 2 hours, and $(i i)$ deposited from a metal $\mathrm{Ti}$ target by reactive sputtering in gas mixture $\mathrm{Ar}$ and $\mathrm{O}_{2}$ with $\mathrm{Ar} / \mathrm{O}_{2}$ molar ratio of $9 / 1$. The $\mathrm{Pt}$ film is prepared with the same sputtering conditions as applied for $\mathrm{Pt} / \mathrm{Ti}$ bilayer.

Later, the substrates are annealed at $750^{\circ} \mathrm{C}$ for 2 hours in a conventional furnace.

The PZT thin film is deposited on $\mathrm{Pt} / \mathrm{TiO}_{2} / \mathrm{SiO}_{2} / \mathrm{Si}$ substrate heated up to $250^{\circ} \mathrm{C}$ by rf-sputtering technique from a multi-element metallic target of $\mathrm{Pb}, \mathrm{Ti}$ and $\mathrm{Zr}$ in a gaseous mixture of $\mathrm{Ar}$ and $\mathrm{O}_{2}$ with $\mathrm{Ar} / \mathrm{O}_{2}$ ratio of 6/4. For the starting target composition $\mathrm{Zr} / \mathrm{Ti}: 7.5 / 8.5$, the average $\mathrm{Zr} / \mathrm{Ti}$ concentration of the PZT film is determined of 51/49 by the electron probe microanalysis [18]. This indicates the PZT thin film is close to the morphotrophic phase boundary (MPB) where the excellent piezo- and ferroelectric properties emerge [19]. After that the samples were annealed at $650^{\circ} \mathrm{C}$ for various times in air.

The crystalline structure of $\mathrm{TiO}_{2}$ and Pt layer, and PZT thin films were examined by X-ray diffraction analysis (XRD). The surface morphology of Pt bottom electrode is investigated by the scanning electron microscope technique (SEM).

\section{RESULTS AND DISCUSSION}

\section{III.1. Pt/Ti electrode}

In Fig. 1, we show the surface morphology of an as-deposited Pt/Ti bilayer. Notice that the bilayer is sputtered on unheated substrate under argon ambience. The SEM image reveals a relative smooth surface without pores, pinholes, etc...

It is well known that hillock growth associated with the $\mathrm{Pt} / \mathrm{Ti}$ electrode occurs during the annealing step in the crystallization of PZT thin films from amorphous into the perovskite structure. These hillocks significantly affect the microstructure and ferroelectric properties. Many experiments have been carried out to study the post-deposition heat treatment dependence of the hillock formation on the Pt surface [11-13]. In oxygen ambience, $\mathrm{Ti}$ and $\mathrm{O}$ atoms diffuse inside the $\mathrm{Pt}$ layer during the annealing procedure, they react each other. $\mathrm{TiO}_{2}$ layer is subsequently formed in the Pt grain boundary, and acts however as a barrier against $\mathrm{Ti}$ - and $\mathrm{O}$-diffusion. Thus $\mathrm{TiO}_{2}$ mainly locates in the middle of the $\mathrm{Pt}$ layer, this cause a large volume expansion and gives rise to a high extrinsic compressive stress. Consequently, the Pt hillocks are formed [11,13]. The hillock size and density normally depend on the Ti and Pt layer thicknesses, the deposition temperature, and increase with annealing temperature. The hillock formation is normally observed at 
the annealing temperature of $500^{\circ} \mathrm{C}$ and continuously grows for temperatures up to $900^{\circ} \mathrm{C}$ $[13,16]$.

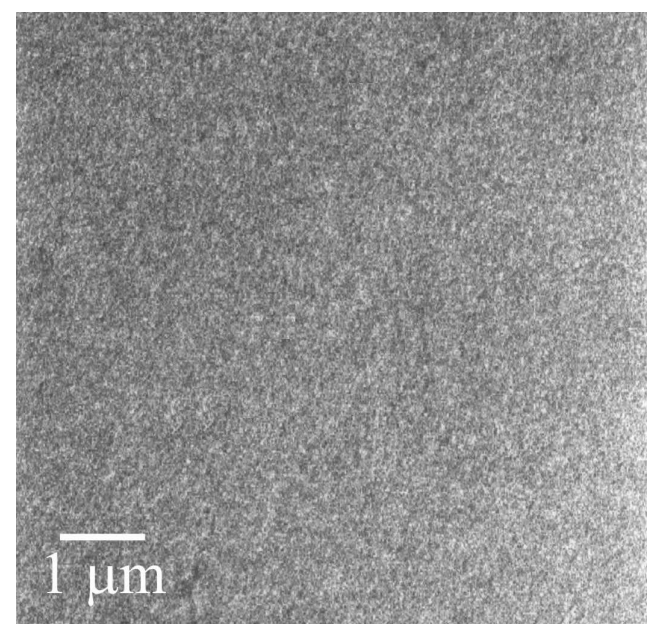

Fig. 1. Scanning electron micrograph (SEM) of as-deposited Pt thin film on the substrate with Ti glue layer. The Ti layer thickness is of $20 \mathrm{~nm}$.

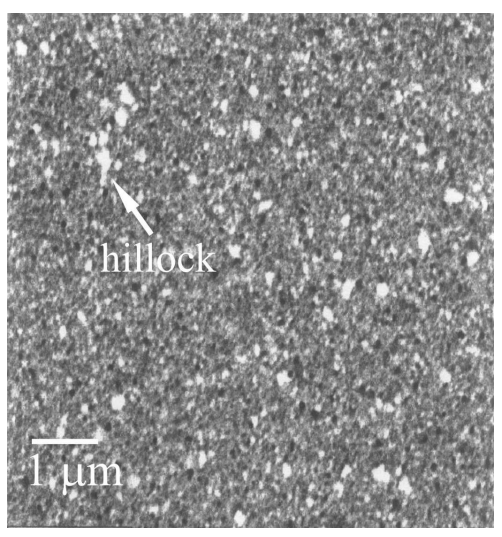

(a)

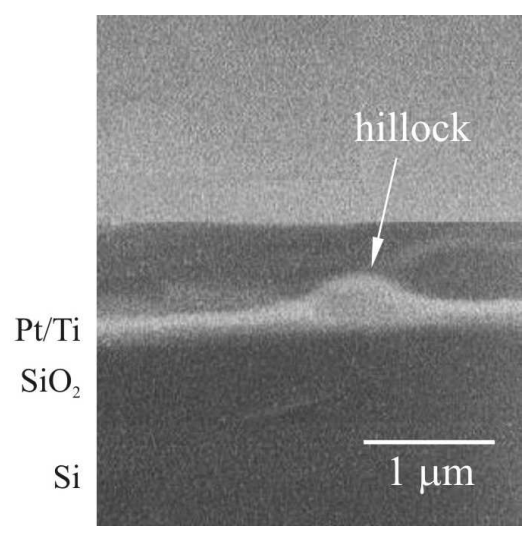

(b)

Fig. 2. SEM image obtained on Pt surface (a) and cross-sectional image (b) of the $\mathrm{Pt} / \mathrm{Ti}$ electrode annealed at $750^{\circ} \mathrm{C}$ for $2 \mathrm{hrs}$. The hillocks are clearly observed. The tiny dark spots are nano-size holes.

By considering the crystallization temperature of PZT thin films (see the caption of Fig. 7), the $\mathrm{Pt} / \mathrm{Ti}$ bottom electrode is annealed at the temperature of $750^{\circ} \mathrm{C}$ for 2 hours in air. The surface profile of the annealed-Pt/Ti/SiO $/ 2 / \mathrm{Si}$ substrate is shown in Fig. 2a. We can see the Pt film surface is much rougher than the one of as-deposited film (as shown in Fig. 1). This is contributed to the hillock growth during heat treatment. The 
cross-sectional SEM image of the substrate in Fig. 2b obviously shows a hillock with a height of approximately $150 \mathrm{~nm}$ on Pt surface. The intermixing between $\mathrm{Pt}$ and Ti layer is hardly observed due to the thin Ti underlayer. The hillock formation can lead to capacitor failure $[12,14]$ and possibly result to a poor ferroelectric properties of our PZT thin film, as reported in our previous work [18]. Moreover, nano-size holes are obtained, likely the tiny dark spots in the left panel of Fig. 2. It is believed the holes affect to the passage of diffusing atoms and out-diffusion for $\mathrm{Ti}$ and $\mathrm{O}$ atoms on the surface [16].

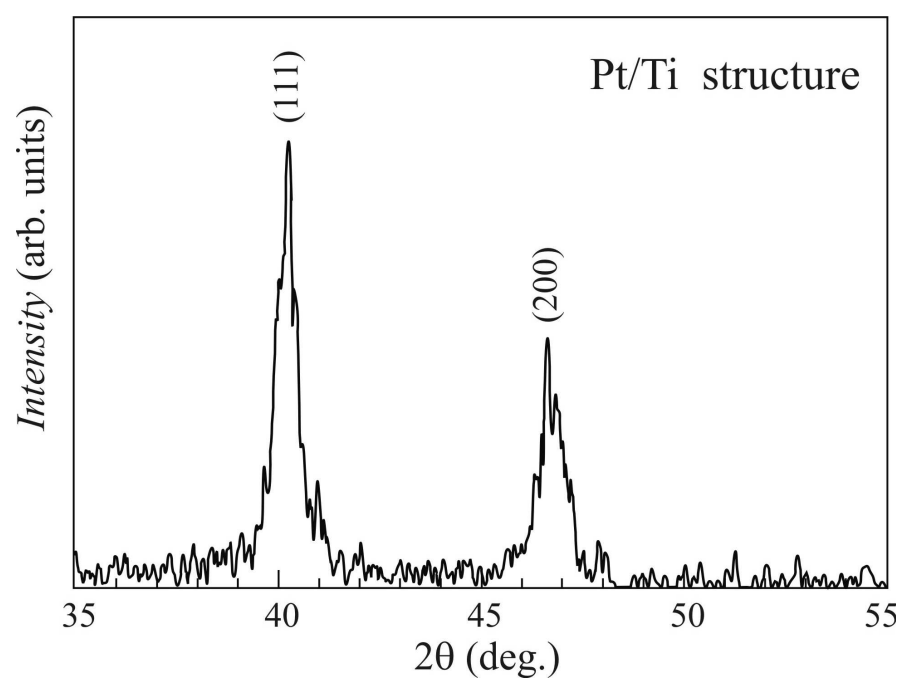

Fig. 3. The X-ray diffraction (XRD) pattern of $\mathrm{Pt} / \mathrm{Ti} / \mathrm{SiO}_{2} / \mathrm{Si}$ metallization annealed at $750^{\circ} \mathrm{C}$ for $2 \mathrm{hrs}$.

In Fig. 3, we show the XRD pattern of a bottom electrode with $\mathrm{Pt} / \mathrm{Ti}$ structure annealed at $750^{\circ} \mathrm{C}$ for 2 hours. The peaks at $2 \theta=40$ and $46.5^{\circ}$ correspond to (111) and (200) planes of the Pt thin film, in which the former one with a stronger intensity reveals the Pt layer orients along the [111]-main direction.

\section{III.2. $\mathrm{Pt} / \mathrm{TiO}_{2}$ electrode}

As above mentioned, the $\mathrm{TiO}_{2}$ layer plays an important role as a barrier against the diffusion of $\mathrm{Ti}$ and $\mathrm{O}$ atoms. Thus a thin $\mathrm{TiO}_{2}$ layer is selected to be a promising adhesion layer for PZT thin films, which can prevent Ti diffusing to the middle of Pt layer, consequently eliminating the hillock formation.

In our study, the thin $\mathrm{TiO}_{2}$ layers are fabricated by two routes: $(i)$ thermally oxidizing a sputtered-Ti thin film in oxygen, and (ii) reactive sputtering $\mathrm{Ti}$ metal in a mixture of $\mathrm{Ar}$ and $\mathrm{O}_{2}$ gas. Investigations on surface profile and crystalline structure of $\mathrm{Pt} / \mathrm{TiO}_{2}$ electrodes with $\mathrm{TiO}_{2}$ underlayer prepared by these ways give very similar results. The data reported in remainder of this section are taken on the substrate with $\mathrm{TiO}_{2}$ layer grown by the oxidized-Ti thin film.

Fig. 4 represents the XRD pattern of the $20 \mathrm{~nm}-\mathrm{TiO}_{2}$ adhesion layer. The peak at 28.5 $5^{\circ}$ indicates $\mathrm{TiO}_{2}$ existing in the anatase structure. We can argue the peak intensity 


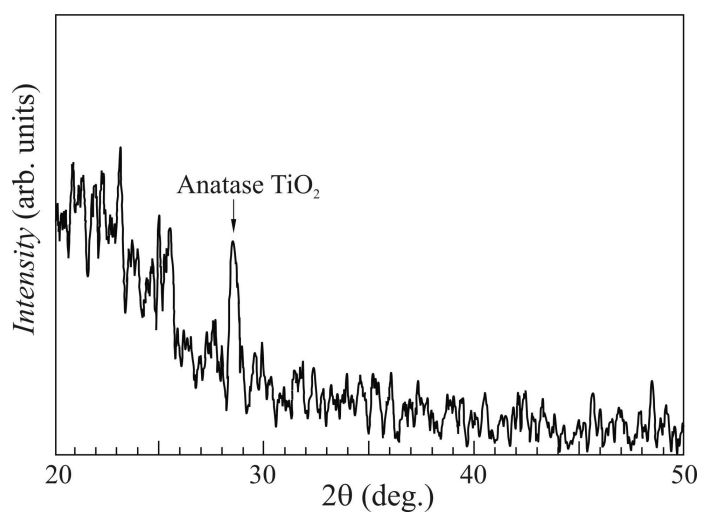

Fig. 4. The XRD pattern of the $\mathrm{TiO}_{2} / \mathrm{SiO}_{2} / \mathrm{Si}$ substrate. The $20 \mathrm{~nm}-\mathrm{TiO}_{2}$ layer was made by oxidizing the sputtered Ti thin film in $\mathrm{O}_{2}$ gas at $750^{\circ} \mathrm{C}$ for $2 \mathrm{hrs}$.

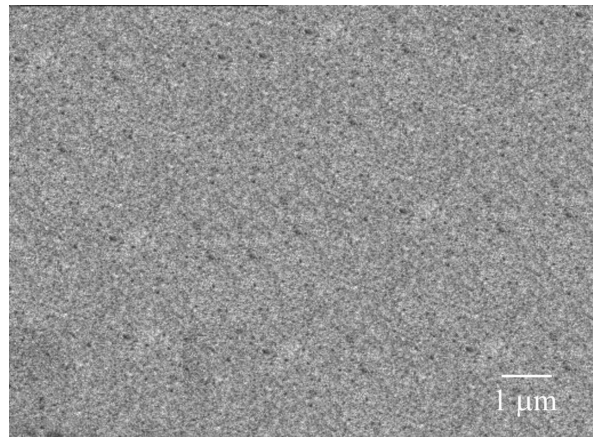

Fig. 5. Surface morphology of $\mathrm{Pt} /$ $\mathrm{TiO}_{2} / \mathrm{SiO}_{2} / \mathrm{Si}$ substrate after annealing at $750^{\circ} \mathrm{C}$ for $2 \mathrm{hrs}$.

is relatively weak and comparable to the background. But this is in agreement with the fact that the $\mathrm{TiO}_{2}$ layer having a thickness of below $100 \mathrm{~nm}$ is not clearly crystallized or consists of microcrystal with random orientation [15].

The SEM image in Fig. 5 shows the surface profile of the substrate with $\mathrm{Pt} / \mathrm{TiO}_{2}$ structure annealed at $750^{\circ} \mathrm{C}$ for 2 hours. Obviously, the Pt surface is flat and uniform without the hillocks.

The XRD pattern of the substrate with $\mathrm{Pt} / \mathrm{TiO}_{2}$ structure annealed at $750{ }^{\circ} \mathrm{C}$ for 2 hours is shown in Fig. 6. Two peaks characterized for the Pt thin film with (111) and (200) planes are observed. The data curve is smooth and shows a large intensity ratio between (111)- and (200)-peak in comparison to those obtained on the substrate with $\mathrm{Pt} / \mathrm{Ti}$ structure (see Fig. 3).

In summary, by using $\mathrm{TiO}_{2}$ as an adhesion layer, we provide a strong evidence for an improvement of the Pt surface morphology, which could satisfy well requirements of integrated capacitor structure for bottom electrodes of PZT thin films.

The annealing time dependence of the crystallization of the $\mathrm{Pb}(\mathrm{Zr}, \mathrm{Ti}) \mathrm{O}_{3}$ thin film deposited on $\mathrm{Pt} / \mathrm{TiO}_{2} / \mathrm{SiO}_{2} / \mathrm{Si}$ substrates at $250^{\circ} \mathrm{C}$ is showed in Fig. 7. Here the PZT thin films with compositional ratio $\mathrm{Zr} / \mathrm{Ti}$ : $51 / 49$ are prepared by the rf-sputtering method from a multi-element metallic target in the gaseous mixture $\mathrm{Ar}+\mathrm{O}_{2}$. To form the PZT perovskite phase, the thin films are annealed at $650^{\circ} \mathrm{C}$ in the air for 30 and $60 \mathrm{~min}$.

We realize that the crystallization of the $\mathrm{PZT}$ thin film sputtered on $\mathrm{Pt} / \mathrm{TiO}_{2}$ substrate is almost the same to one deposited on Pt/Ti substrate, reported in Refs.[10,18,20]. For as-deposited PZT film, the XRD pattern shows the peaks due to $\alpha-\mathrm{PbO}_{2}$ and fluorite $\mathrm{Pb}_{2} \mathrm{Ti}_{2} \mathrm{O}_{6}$ phases, while $\mathrm{ZrO}_{2}$ and $\mathrm{TiO}_{2}$ are suggested in amorphous phases. Notice that all $\mathrm{Pb}, \mathrm{Ti}, \mathrm{Zr}$ are oxidized at the same time on sputtering procedure. After annealing at $650^{\circ} \mathrm{C}$, the PZT perovskite phase is observed. This is contributed to solid phase reactions between the intermediate phases which are formed during heat treatment, i.e. lead-rich $\mathrm{PbO}_{s}$ and lead-deficient $\mathrm{Pb}(\mathrm{Ti}, \mathrm{Zr})_{3} \mathrm{O}_{7}$ phases [20]. The single-perovskite phase with the 


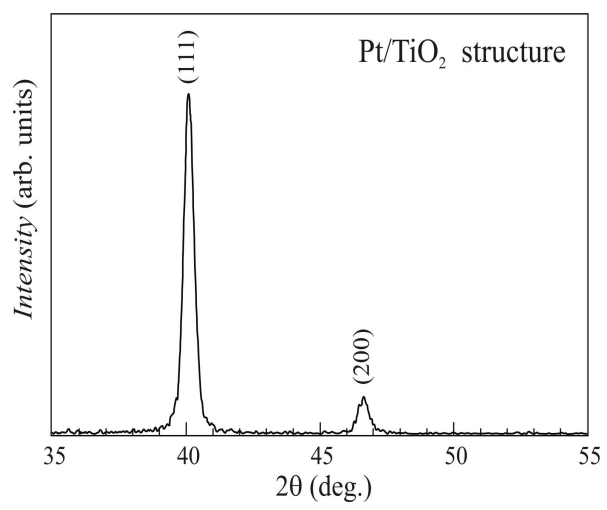

Fig. 6. The XRD pattern of $\mathrm{Pt} /$ $\mathrm{TiO}_{2} / \mathrm{SiO}_{2} / \mathrm{Si}$ substrate annealed at $750^{\circ} \mathrm{C}$ for $2 \mathrm{hrs}$.

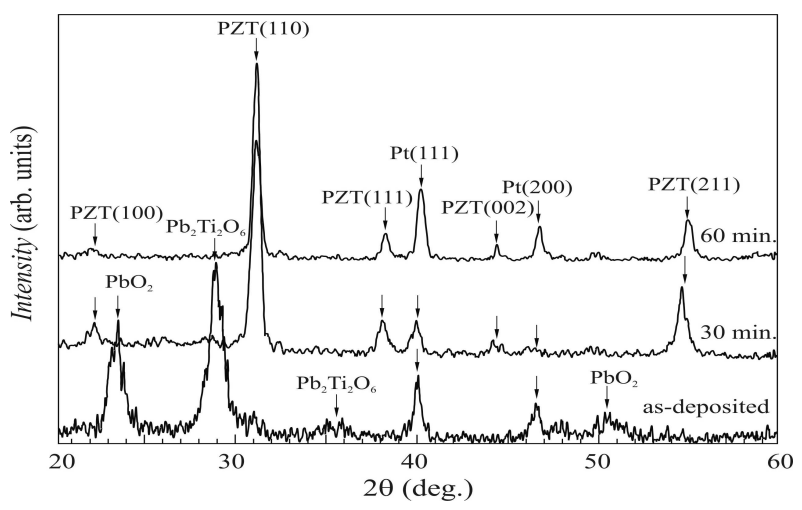

Fig. 7. The XRD pattern of the PZT thin films grown on $\mathrm{Pt} / \mathrm{TiO}_{2} / \mathrm{SiO}_{2} / \mathrm{Si}$ substrates annealed at $650^{\circ} \mathrm{C}$ in air for various annealing times: 30 and 60 min., respectively, from bottom to up.

(110)-preferred orientation occurs in the thin films annealed for $30 \mathrm{~min}$. With the annealing time of $60 \mathrm{~min}$., the single PZT phase is completely obtained, and we could not detect any trace of secondary phases in the thin film. The post-deposition annealing for longer times has been not carried out yet. Nevertheless, it is believed that the lead-deficient pyrochlore phase considered as the defect ferroelectric phase will predominantly emerges due to $\mathrm{Pb}$ evaporation in the PZT films annealed for a long time at high temperatures [18].

\section{CONCLUSION}

The influences of the adhesion layers of $\mathrm{Ti}$ or $\mathrm{TiO}_{2}$ on both the surface morphology and crystalline structure of the Pt bottom electrodes severed as a substrate for the PZT thin films were investigated. The hillock formation, which may cause poor electrical properties of the PZT films, was observed on Pt surface for the case of the substrate with Ti glue layer. However, the surface profile of the substrate was significantly improved by replacing of $\mathrm{TiO}_{2}$ adhesion layer. The $\mathrm{Pt}$ surface became flat and uniform. Further more, the formation of the PZT perovskite phase during the annealing procedure was mentioned. It indicates that the single-PZT phase completely obtained for the thin film annealed at $650^{\circ} \mathrm{C}$ in the air for one hour. For the further studies, we will focus on measuring the electrical and ferroelectric properties of PZT thin films deposited on the $\mathrm{Pt} / \mathrm{TiO}_{2} / \mathrm{SiO}_{2} / \mathrm{Si}$ substrate.

\section{REFERENCES}

[1] .F. Scott and C.A. Paz de Araujo, Science 246 (1989) 1400.

[2] . Muralt, J. Micromech. Microeng. 10 (2000) 136.

[3] . Sreenivas, I. Reaney, T. Maeder, N. Setter,C. Jagadish and R.G. Elliman, J. Appl. Phys. 75 (1994) 232.

[4] .C. Jeon, J.M. Seon, J.H. Joo, K.Y. Oh, J.S. Roh and J. Kim, Appl. Phys. Lett. 71 (1997) 467.

[5] . Nakamura, Y. Nakao, A. Kamisawa and H. Takasu, Appl. Phys. Lett. 65 (1994) 1522. 
INFLUENCE OF ADHESION LAYERS ON THE SURFACE MORPHOLOGY OF PLATINUM-BASED ... 57

[6] .B. Lee, S. Tirumala and S.B. Desu, Appl. Phys. Lett. 74 (1999) 1484.

[7] . Maiwa, N. Ichinose and K. Okazaki, Jpn. J. Appl. Phys. 33 (1994) 5223.

[8] .H. Park, C.Y. Kim, Y.W. Jeong, H.J. Kwon, K.Y. Kim, J.S. Lee and S.T. Kim, J. Mater. Res. 10 (1995) 1790.

[9] . Velu and D. Remiens, J. Eur. Ceram. Soc. 19 (1999) 2005.

[10] . Thomas, S. Mochizuki, T. Mihara and T. Ishida, Mater. Sci. Eng. B 95 (2002) 36.

[11] .J. Nam, D.K. Choi and W.J. Lee, Thin Solid Films 371 (2000) 264.

[12] .Y. Kweon, S.K. Choi, S.J. Yeom and J.S. Roh, Jpn. J. Appl. Phys. 40 (2001) 5850.

[13] .W. Jung, S.K. Choi, S.Y. Kweon and S.J. Yeom, Appl. Phys. Lett. 83 (2003) 2160.

[14] .Y. Kweon, S.J. Yeon, H.J. Sun, N.K. Kim, Y.S. Yu and S.K. Lee, Integr. Ferroelectr. 25 (1999) 299.

[15] . Abe, Y. Otani, M. Miyake, M. Kurita, H. Takeda, S. Okamura and T. Shiosaki, Jpn. J. Appl. Phys. 42 (2003) 2791.

[16] .S. Jeong, H.U. Lee, S.A. Lee, J.P. Kim, H.G. Kim, S.Y. Jeong, C.R. Cho, Current Appl. Phys. 9 (2009) 115.

[17] . Zhong, J. Peng, S. Zhang and W. Zhang, Integr. Ferroelectr. 80 (2006) 281.

[18] .T. Huy, V.N. Hung and N.P. Thuy, J. Sci.: Math.-Phys. (VNU, Hanoi, T. XX) 1 (2004) 31.

[19] . Damjanovic, Rep. Prog. Phys. 61 (1998) 1267.

[20] .V.R. Vasant Kumar, R. Pascual and M. Sayer, J. Appl. Phys. 71 (1992) 864.

Received 28 November 2008. 